\title{
Analysis of Optimum Performance of Air Vessels Used in Damping Water Hammer Pressure Wave
}

\author{
Ahmed Ashraf Abdelfattah ${ }^{1}$, Ashraf Moustafa ${ }^{2}$, A.M. Abdulaziz ${ }^{3}$ \\ ${ }^{1}$ Mechanical Engineer, Dar Alhandasah, Cairo, Egypt \\ G16111615@eng.asu.edu.eg \\ m.e.ahmed.ashraf@gmail.com \\ Tel. +201220501381 \\ ${ }^{2}$ Ain Shams University, Faculty of Engineering, \\ Department of Mechanical Power Engineering, Cairo, Egypt \\ Ashraf.mostaf@eng.asu.edu.eg \\ Tel. +201025672108 \\ ${ }^{3}$ Ain Shams University, Faculty of Engineering \\ Department of Mechanical Power Engineering, Cairo, Egypt \\ abdelaziz_morgan@eng.asu.edu.eg \\ Tel. +201227912259
}

\begin{abstract}
Transient flow or water hammer is the sudden change of flow conditions due to an unexpected event such as a sudden closing of a valve installed on the pipeline system. Water hammer can pose serious threats to the pipeline system, as the flow's pressure can be changed above or below the limits which the pipeline network can withstand. Controlling the water hammer pressure becomes indispensable, so a transient surge analysis is required to investigate the points of severe changes along with the pipeline system. Compressed air vessel (CAV) is a pressure control device that is used to control the positive and negative pressure changes. There are two parameters affect the sizing of the air vessel; the initial trapped air volume and throttling the aperture of the air vessel. A computer model based on the unsteady one-dimensional flow equations of momentum and continuity is established to examine the proper size of the two parameters. The equations are solved by the method of characteristics while the vessel is modeled as a quasi-one-dimensional flow system. An experimental test rig provided with a rapid closing magnetic valve and pressure sensors are used to validate the model results. Both the experimental and model results show the high capability of the air vessel to dampen water hammer pressure. In addition, the results show that the introduced throttling action has a wide effect on the size of the air vessel and that the diameter of the throttling shall not be less than 0.3 the diameter of the main pipe. Besides, the initial volume
\end{abstract}


of the trapped air should be in the range of $53 \%$ to $78 \%$ of the total volume of the air vessel, so that the air vessel works effectively with optimum value of $60 \%$.

\section{Keywords}

Water hammer, transient flow, compressed air vessel, mathematical modeling

\section{Nomenclatures:}

$A_{1} \quad$ pipe area of upstream air vessel, $\mathrm{m}^{2}$

$A_{2} \quad$ pipe area of downstream air vessel, $\mathrm{m}^{2}$

$A_{C A V} \quad$ Area of the air vessel, $\mathrm{m}^{2}$

$A_{\text {orifice }}$ Area of the orifice, $\mathrm{m}^{2}$

a Sound speed, $\mathrm{m} / \mathrm{s}$

C1,C2,C3 Coefficients of pump equation

$C_{d} \quad$ Discharge coefficient

D Diameter of the pipe, $\mathrm{mm}$

E Young's modulus

e Thickness of the pipe, $\mathrm{mm}$

$f \quad$ Friction coefficient

G Gravity acceleration, $\mathrm{m} / \mathrm{s}^{2}$

$\mathrm{H}$ Pressure head, $\mathrm{m}$

$\mathrm{K} \quad$ Bulk modulus, $\mathrm{Pa}$

$\mathrm{k} \quad$ Iteration level

$\mathrm{L} \quad$ Length of the pipe, $\mathrm{m}$

$\mathrm{N}$ Grid mesh points number

$P_{\text {air }} \quad$ Absolute pressure of air, $\mathrm{Pa}$

$p$ Pressure, $\mathrm{Pa}$

$Q \quad$ Water flow rate, $\mathrm{m}^{3} / \mathrm{s}$

S Sample

s Second

$T_{c} \quad$ Closure time of valve, $\mathrm{s}$

$\mathrm{t}$ Time of wave travel, $\mathrm{s}$

$\Delta t \quad$ Time step, $\mathrm{s}$

$V_{o} \quad$ Velocity of the flow, $\mathrm{m} / \mathrm{s}$

$V \quad$ Velocity, $\mathrm{m} / \mathrm{s}$

$\forall_{\text {air }} \quad$ Volume of trapped air inside air vessel, $\mathrm{m}^{3}$

$\forall_{C A V} \quad$ Volume of compressed air vessel, $\mathrm{m}^{3}$

$x \quad$ Distance along pipe, $\mathrm{m}$

$\Delta x \quad$ Mesh size in $\mathrm{x}$-direction, $\mathrm{m}$

$z \quad$ Elevation, $\mathrm{m}$

$Z_{w} \quad$ Height of water column inside air vessel, $\mathrm{cm}$ 


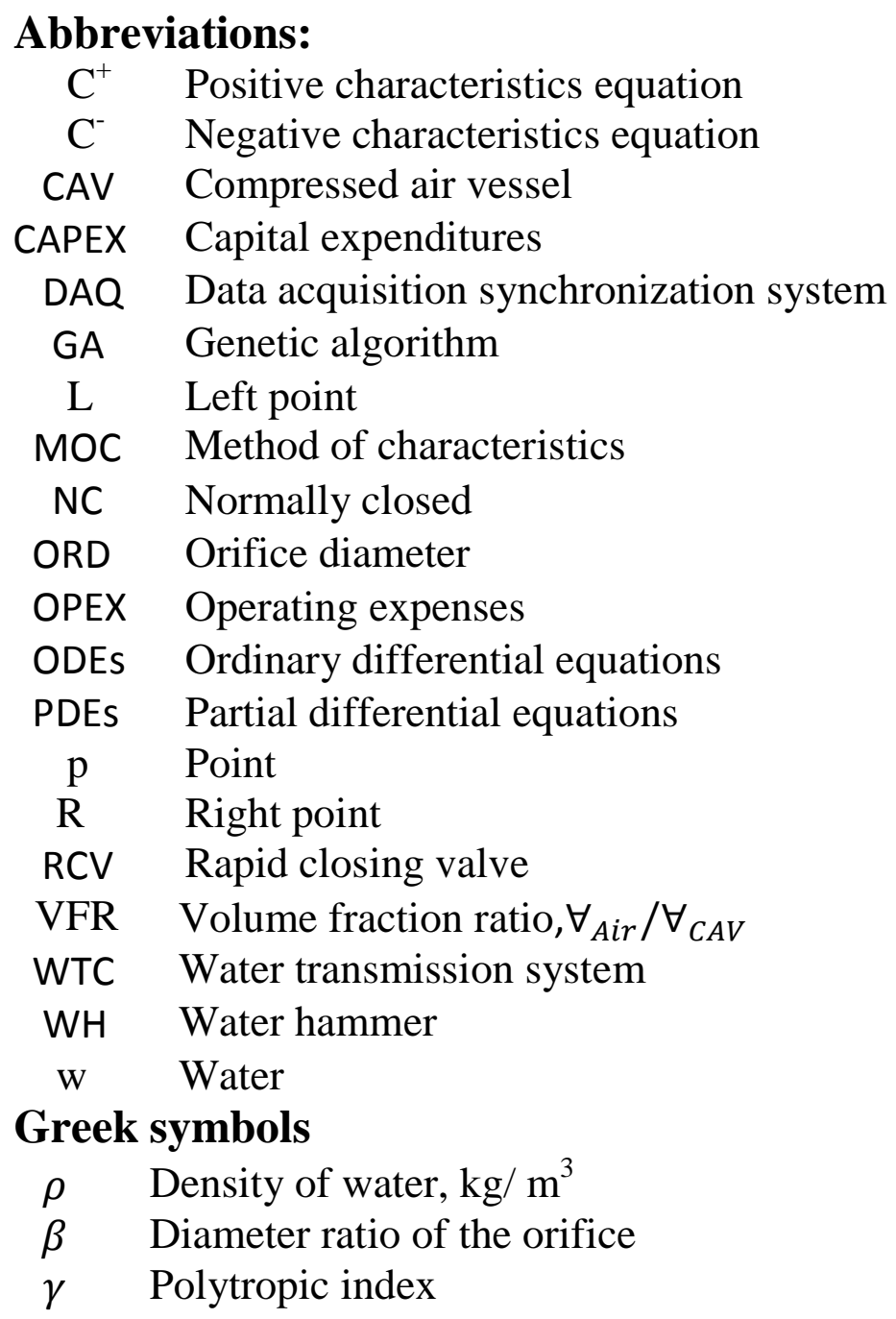




\section{Introduction}

The CAPX and OPEX for the water pipeline network are very high, as the prices of the components of the piping line have been raised in the recent decades; so transient control devices should be provided to the water piping line to keep the water pressure limited to the pressure rating of the piping line and appurtenances. A good design means providing a reliable, secured, efficient, effective, and sustainable system with optimal budget. Accordingly, a surge analysis is carried out for the water piping system, to forecast the undesirable scenarios for the flow, which can cause the transient action [1]. Upon predicting the sources of the transient flow; we can decide the proper transient control device. The transient action occurred, leads to the water hammer phenomena which resembles the loud banging hammering noise. Water hammer is considered a hazard for the water piping line, as it results in building up of pressure inside the pipes which can exceed the pressure rating of the pipes, so utilizing a transient control devices has becoming indispensable for the water piping line.

Instant valve closure is one of the causes of the water hammer, as it results in abrupt change in the head above the predetermined rated values [2]. The Water hammer pressure change has been described by the well-known Joukowsky's fundamental equation of water hammer [3]. Utilizing the mass and momentum equations; the two familiar one-dimensional governing equations for the transient flow have been formulated, the two equations consider all the physical parameters necessary to model the transient flow [3]. Several approaches have been developed to solve the governing equations of the transient flow. The method of characteristics (MOC) has been introduced and found to be an efficient method for solving the transient flow [4] and [5].

Several methods of controlling the water hammer have been addressed in research papers and books, among these methods are the air vessels. The air vessel is defined as a vessel which contains two fluids in contact with each other, liquid at the bottom and compressed air at the upper level [6,7]. The air vessel makes use of the compressibility factor of the air to dampen the pressure rising inside the pipeline, the air vessel can be comparable to, and in some cases superior to other transient control devices since it can control the positive and negative pressure changes [8]. The air vessel is incorporated into the piping line, the extent to which is determined by several factors including the pipeline profile [9].The performance of the air vessel is affected by the process on which the entrapped air is undergoing during the water hammer event. The water hammer happens in a relatively small-time interval, through which the compression and expansion of air process can be considered an adiabatic process with a constant polytropic index equal to $1.2[9,10]$. Throttling the inflow to the air vessel is recommended to increase the effectiveness of the air vessel allowing smaller air vessel sizes could be achieved $[11,13]$. The volume of 
entrapped air, inside the air vessel, represents the keyword of the air vessel performance, so it must be controlled so as to maintain the amount of air inside the vessel due to the solubility of air in the liquid [11,12]. A plenty of graphs, for the preliminary design to calculate the air vessel's volume, have been established based on knowing the maximum and minimum head along the pipeline $[9,14]$. Also, the installation mode and position of the air vessel, either horizontal or vertical has been introduced in research works which has no effect on water hammer [15]. Experiments have been conducted to examine the performance of the air vessel on damping the water hammer [16]. A Genetic Algorithm (GA) method has been used; to optimize the volume of the air chamber [17]. The air chamber was found to be a good device to control the up and down surge as demonstrated in pressure along pipeline network.

The main objective of this paper is to optimize the size of the air vessel, used to dampen the water hammer phenomena, through studying two parameters: the orifice diameter and the volume of entrapped air. A mathematical modelling, using FORTRAN programming language, will be established. The results will be validated with the carried experiments to explore the water hammer phenomena and the action of air chamber to dampen the pressure rise due to water hammer.

\section{Methodology}

The modelling of the transient flow is governed by two basic partial differential equations, namely, conservation of mass and conservation of momentum. Since the piping system is composed of pipes of long lengths compared to their diameters, the flow is simplified to a one-dimensional unsteady flow. The test system is composed of a long pipe which has a pump from one end and a rapid closing valve, RCV, at the outlet end. The compressed air vessel exists just before the valve, to dampen the water hammer.

\subsection{Governing equations}

- Conservation of momentum

$\frac{\partial \mathrm{V}}{\partial \mathrm{t}}+\frac{1}{\rho} \frac{\partial \mathrm{p}}{\partial \mathrm{x}}+\mathrm{g} \frac{\mathrm{dz}}{\mathrm{dx}}+\frac{\mathrm{f}}{2 \mathrm{D}} \mathrm{V}|\mathrm{V}|=0$

- Conservation of mass

$\mathrm{a}^{2} \frac{\partial \mathrm{V}}{\partial \mathrm{x}}+\frac{1}{\rho} \frac{\partial \mathrm{p}}{\partial \mathrm{t}}=0$

Where $\mathrm{a}$ is the speed of sound of water in pipes

$$
\mathrm{a}=\frac{\sqrt{\mathrm{K} / \rho}}{\sqrt{1+\frac{\mathrm{K} * \mathrm{D}}{\mathrm{E} * \mathrm{e}}}}
$$


All parameters are indicated in the nomenclature.

The method of characteristics is used to transform the PDEs (1 and 2) to ODEs valid along certain lines called the characteristic lines, $C^{+}$and $C^{-}$. The DEs are then solved using finite difference explicit scheme to get the velocity and head at each mesh point along the pipe. The computational grid used in this mathematical modeling is shown in Fig. 1 where $\Delta x$ is the mesh distance and $\Delta t$ is the time step. For an interior point, the characteristic equations are

$$
\begin{gathered}
C^{+}:\left(V_{p}^{(k)}-V_{L}^{(k-1)}\right)+\frac{g}{a}\left(H_{p}^{(k)}-H_{L}^{(k-1)}\right)+\frac{f}{2 D} \times \Delta t \times V_{L}^{(k-1)} \times\left|V_{L}^{(k-1)}\right|=0 \\
C^{-}:\left(V_{p}^{(k)}-V_{R}^{(k-1)}\right)-\frac{g}{a}\left(H_{p}^{(k)}-H_{R}^{(k-1)}\right)+\frac{f}{2 D} \times \Delta t \times V_{R}^{(k-1)} \times\left|V_{R}^{(k-1)}\right|=0
\end{gathered}
$$

Where $\mathrm{p}$ denotes the point under consideration, $\mathrm{L}$ is the left value, $\mathrm{R}$ is the right value, $\mathrm{k}$ is the new value and $\mathrm{k}-1$ is the previous value.

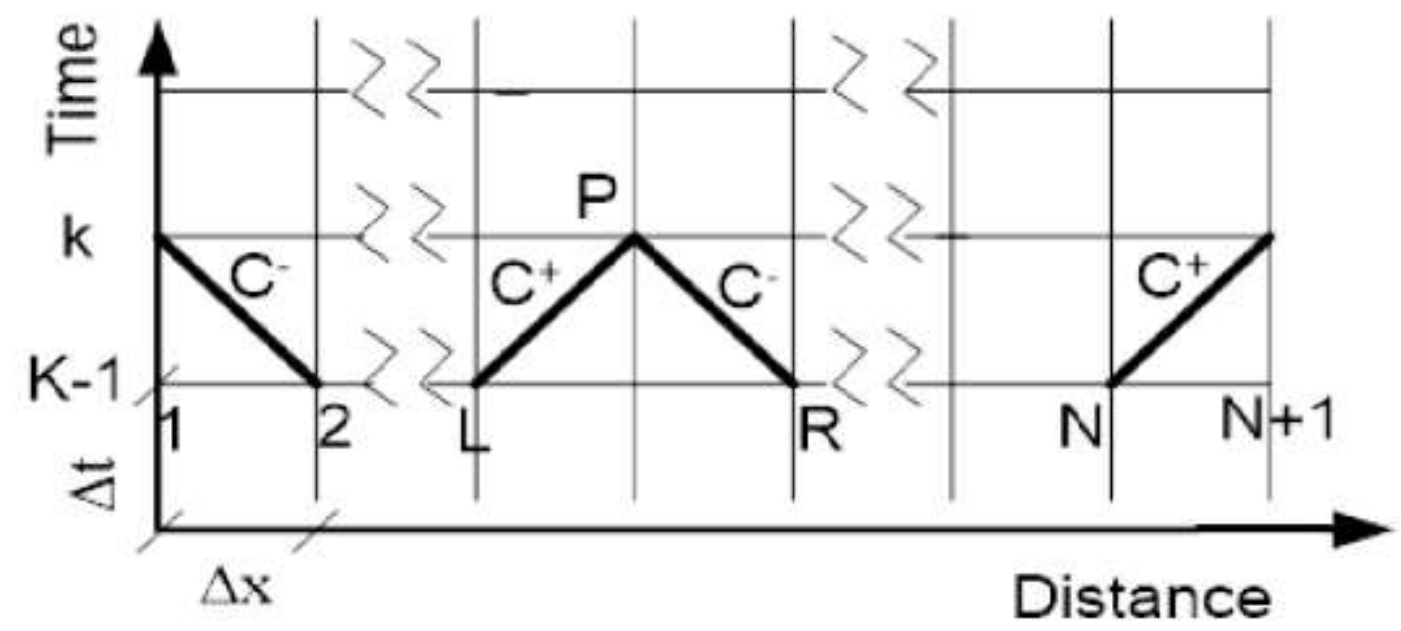

Fig.1 One-dimensional computation grid of the physical problem

\subsection{Boundary Conditions}

a) Constant speed pump at pipe entrance

Using the Negative Characteristic equation,

$\mathrm{C}^{-}:\left(\mathrm{V}_{1}^{(\mathrm{k})}-\mathrm{V}_{2}^{(\mathrm{k}-1)}\right)-\frac{\mathrm{g}}{\mathrm{a}}\left(\mathrm{H}_{1}^{(\mathrm{k})}-\mathrm{H}_{2}^{(\mathrm{k}-1)}\right)+\frac{\mathrm{f}}{2 \mathrm{D}} \times \Delta \mathrm{t} \times \mathrm{V}_{2}^{(\mathrm{k}-1)} \times\left|\mathrm{V}_{2}^{(\mathrm{k}-1)}\right|=0$

And the quadratic equation form of the pump

$\mathrm{H}_{1}^{\mathrm{k}}=\mathrm{c}_{1}\left(\mathrm{~V}_{1}^{\mathrm{k}}\right)^{2}+\mathrm{c}_{2} \mathrm{~V}_{1}^{\mathrm{k}}+\mathrm{c}_{3}$

The head, $H_{1}^{k}$ and velocity, $V_{1}^{k}$ at pipe left end can be obtained.

b) Rapid Closure Valve, RCV, at pipe far end

The RCV closes according the following:

$\mathrm{V}_{\mathrm{N}+1}^{(\mathrm{k})}=\mathrm{V}_{0}\left(1-\frac{\mathrm{t}}{\mathrm{T}_{\mathrm{c}}}\right), 0 \leq \mathrm{t} \leq \mathrm{T}_{\mathrm{c}}$

$\mathrm{V}_{\mathrm{N}+1}^{(\mathrm{k})}=0, \mathrm{t}>\mathrm{T}_{\mathrm{c}}$ 
And the Positive Characteristic equation

$\mathrm{C}^{+}:\left(\mathrm{V}_{\mathrm{N}+1}^{(\mathrm{k})}-\mathrm{V}_{\mathrm{N}}^{(\mathrm{k}-1)}\right)+\frac{\mathrm{g}}{\mathrm{a}}\left(\mathrm{H}_{\mathrm{N}+1}^{(\mathrm{k})}-\mathrm{H}_{\mathrm{N}}^{(\mathrm{k}-1)}\right)+\frac{\mathrm{f}}{2 \mathrm{D}} \times \Delta \mathrm{t} \times \mathrm{V}_{\mathrm{N}}^{(\mathrm{k}-1)} \times\left|\mathrm{V}_{\mathrm{N}}^{(\mathrm{k}-1)}\right|=0$

Both head, $\mathrm{H}_{\mathrm{N}+1}^{(\mathrm{k})}$ and velocity, $\mathrm{V}_{\mathrm{N}+1}^{(\mathrm{k})}$, at pipe far end can be obtained.

c) Compressed air Vessel, CAV

The model of the CAV is shown in Fig. 2. The pipe connected to the CAV is composed of two pipes, one on the left and the other is on the right. Both pipes are connected to the vessel through an orifice fitted in a short pipe. The whole group is considered as a $\mathrm{T}$ junction of constant pressure boundary. The set of governing equations are explained:

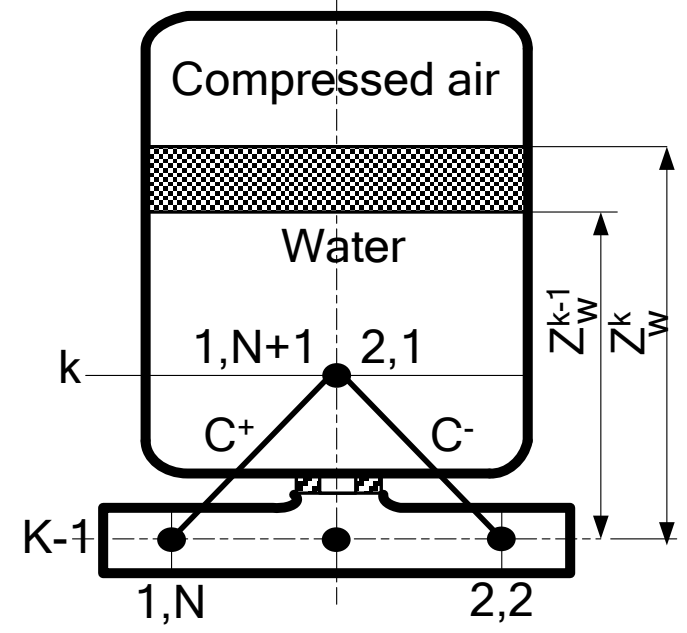

Fig. 2 Compressed air vessel model

1. The positive and negative characteristics for left and right pipes are:

$\mathrm{C}^{+}:\left(\mathrm{V}_{1, \mathrm{~N}+1}^{(\mathrm{k})}-\mathrm{V}_{1, \mathrm{~N}}^{(\mathrm{k}-1)}\right)+\frac{\mathrm{g}}{\mathrm{a}}\left(\mathrm{H}_{1, \mathrm{~N}+1}^{(\mathrm{k})}-\mathrm{H}_{1, \mathrm{~N}}^{(\mathrm{k}-1)}\right)+\frac{\mathrm{f}}{2 \mathrm{D}_{1}} \times \Delta \mathrm{t} \times \mathrm{V}_{1, \mathrm{~N}}^{(\mathrm{k}-1)} \times\left|\mathrm{V}_{1, \mathrm{~N}}^{(\mathrm{k}-1)}\right|=0$

$\mathrm{C}^{-}:\left(\mathrm{V}_{2,1}^{(\mathrm{k})}-\mathrm{V}_{2,2}^{(\mathrm{k}-1)}\right)-\frac{\mathrm{g}}{\mathrm{a}}\left(\mathrm{H}_{2,1}^{(\mathrm{k})}-\mathrm{H}_{2,2}^{(\mathrm{k}-1)}\right)+\frac{\mathrm{f}}{2 \mathrm{D}_{2}} \times \Delta \mathrm{t} \times \mathrm{V}_{2,2}^{(\mathrm{k}-1)} \times\left|\mathrm{V}_{2,2}^{(\mathrm{k}-1)}\right|=0$

where $\mathrm{V}_{1, \mathrm{~N}+1}^{(\mathrm{k})}, \mathrm{H}_{1, \mathrm{~N}+1}^{(\mathrm{k})}$ denote the velocity and head at the end of the first pipe (left) at new time step. $\mathrm{V}_{2,1}^{(\mathrm{k})}$ and $\mathrm{H}_{2,1}^{(\mathrm{k})}$ denote the velocity and head at the entrance of the second pipe (right) at new time step. K-1 denotes the old-time step. 
2. Constant pressure model is assumed at the junction

$\mathrm{H}_{1, \mathrm{~N}+1}^{\mathrm{k}}=\mathrm{H}_{2,1}^{\mathrm{k}}$

3. Continuity equation across the junction

$\mathrm{V}_{1, \mathrm{~N}+1}^{(\mathrm{k})} \times \mathrm{A}_{1}-\mathrm{V}_{2,1}^{(\mathrm{k})} \times \mathrm{A}_{2}=\mathrm{Q}_{\mathrm{p}_{\text {orifice }}}^{(\mathrm{k})}$

4. The new water level in the vessel is

$$
\mathrm{Z}_{\mathrm{w}}^{\mathrm{k}}=\mathrm{Z}_{\mathrm{w}}^{\mathrm{k}-1}+\frac{\left(\mathrm{Q}_{\mathrm{p}_{\text {orifice }}}^{(\mathrm{k})}+\mathrm{Q}_{\mathrm{p}_{\text {orifice }}}^{(\mathrm{k}-1)}\right) \Delta \mathrm{t}}{2 \mathrm{~A}_{\mathrm{v}}}
$$

5. The new air volume in the vessel is

$$
\forall_{\mathrm{air}}^{\mathrm{k}}=\forall_{\mathrm{CAV}}-\mathrm{A}_{\mathrm{CAV}} \times \mathrm{Z}_{\mathrm{w}}^{\mathrm{k}}
$$

6. The trapped air located on the top level of the tank undergoes an isentropic compression

$$
\mathrm{p}_{\mathrm{air}}^{\mathrm{k}}=\mathrm{p}_{\mathrm{air}}^{\mathrm{k}-1}\left(\frac{\forall_{\mathrm{air}}^{\mathrm{k}-1}}{\forall_{\mathrm{air}}^{\mathrm{k}}}\right)^{\gamma}
$$

7. The new head at junction point is

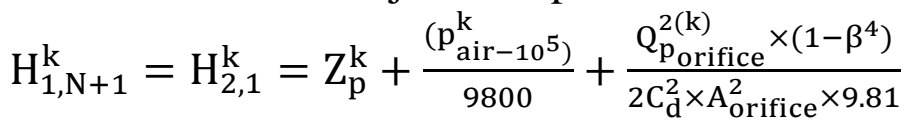

A simulation program is written in FORTRAN language to solve Eqs. (4 - 5) of the interior pipe points, Eqs. $(6-7)$ for the pipe entrance, Eqs. $(8-9)$ for the pipe end and Eqs. $(10-17)$ for the CAV. The results will be compared with the experimental as will be explained later.

\section{Experimental Setup}

Figure. 3 shows a schematic drawing for the simulated test rig, installed in the Faculty Fluid Mechanics Lab, which is a closed water loop mainly consisting of a constant head water tank, centrifugal pump and a copper coil ends with a rapid closing magnetic valve, RCV. The coil dimensions are 15-meter long and $11.5 \mathrm{~mm}$ internal diameter. A Compressed air vessel, $\mathrm{CAV}$, of height $55 \mathrm{~cm}$ and diameter 5 $\mathrm{cm}$ is installed upstream the RCV and is fabricated from Acrylic Transparent Glass to facilitate the monitoring of the water flow inside it. To maintain the volume of air at the presetting values; the CAV is connected to a constant pressure compressed air source to supply it with the required quantity of air. One pressure transducer is mounted very close to the RCV and another one is mounted on the top of the CAV. 
The transducers specifications are shown in Table 1. The pressure transducers are calibrated against pre-calibrated Bourdon tube pressure gauges.

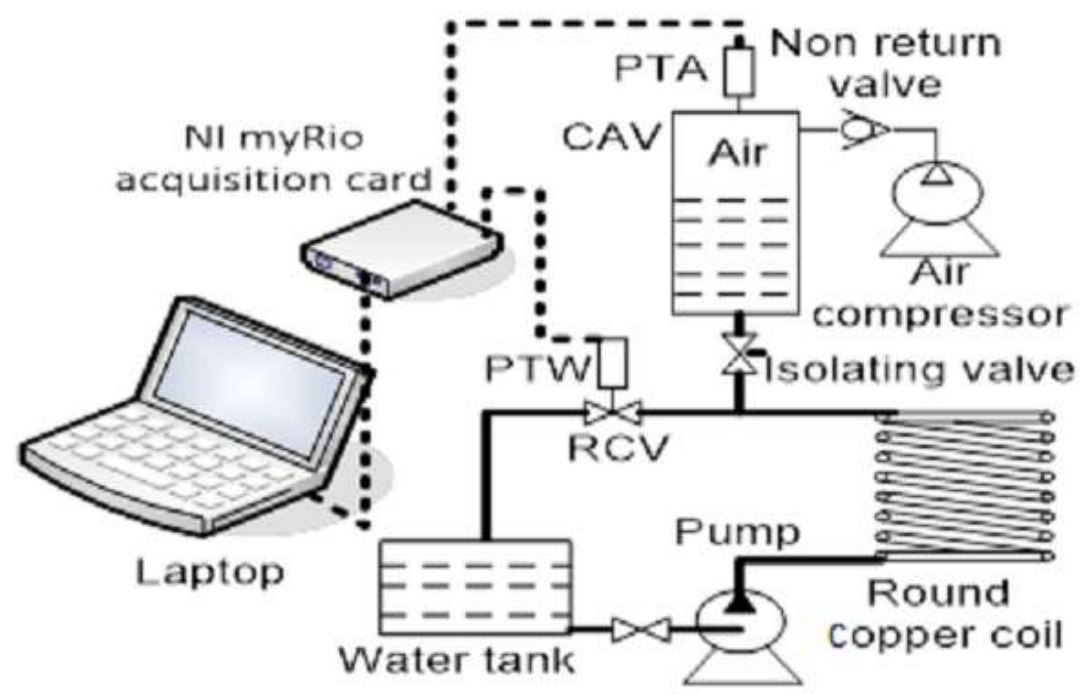

Fig. 3 Experimental test rig set up

Table.1 Pressure transducer specifications

\begin{tabular}{c|c|c} 
Brand & \multicolumn{2}{|c}{ BD-sensor } \\
\hline Output signal & \multicolumn{2}{|c}{ 0 -10V DC } \\
\hline Connection & \multicolumn{2}{|c}{$1 / 4$ NPT male } \\
\hline \multirow{2}{*}{ Measuring range (bar) } & $\min$ & -1 \\
\cline { 2 - 3 } & $\max$ & 40 \\
\hline Max temperature ${ }^{0} \mathrm{C}$ & \multicolumn{2}{|c}{$\mathbf{7 0}$} \\
\hline Accuracy & \multicolumn{2}{|c}{$0.5 \%$ of full scale }
\end{tabular}

The RCV construction is shown in Fig.4 and its specifications are indicated in Table.2. The RCV solenoid receives a signal from a control circuit to open for a predetermined time and closes very rapidly. The pressures signals are monitored on a digital oscilloscope and recorded using NI myRIO acquisition card which has 16 bits DC resolution and maximum sampling rate $200 \mathrm{kS} / \mathrm{s}$.

The correct choice of RCV should be based on the well-known water hammer relation:

$$
\mathrm{T}_{\mathrm{c}}<\frac{2 \mathrm{~L}}{\mathrm{a}} \quad \mathrm{T}_{\mathrm{c}}<\frac{2 \times 15}{1000} \quad \mathrm{~T}_{\mathrm{c}}<30 \mathrm{~ms}
$$

Where $T_{c}$ is the closing time of $R C V, L$ is the pipe length and $a$ is the sonic speed of water in the pipe coil. Unless the closing time is less than $30 \mathrm{~ms}$, the water hammer 
will not occur. According to Table.2 the closing time of RCV is $20 \mathrm{~ms}$ which fulfils the requirements.

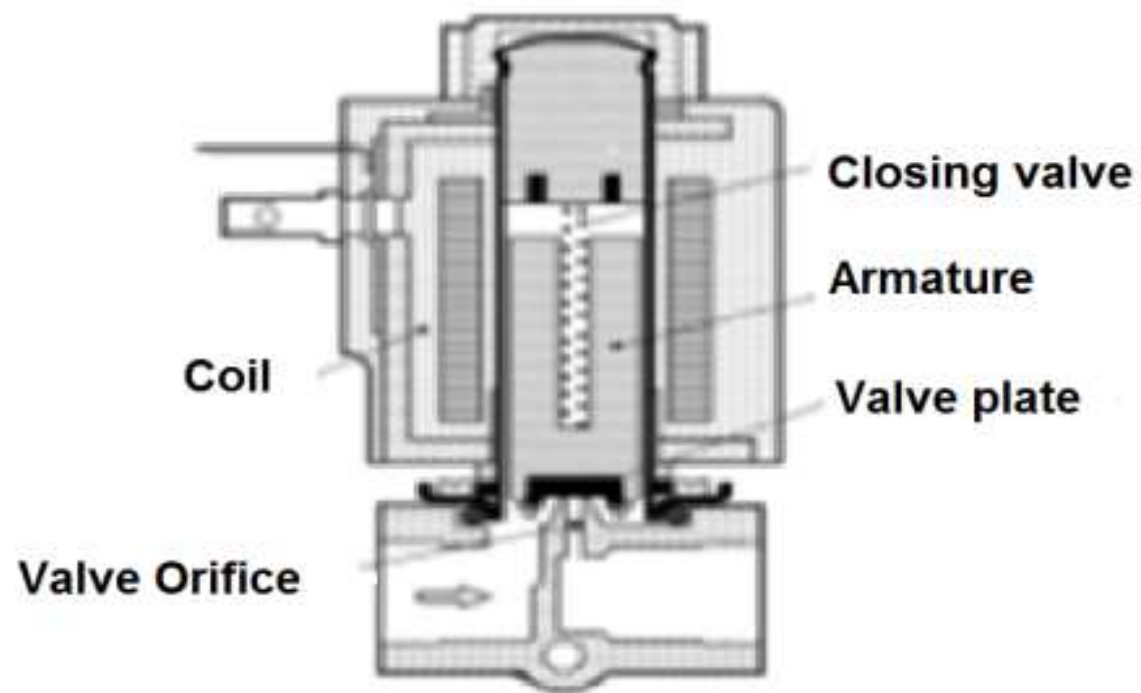

Fig.4 Rapid closing valve, RCV.

Table.2 Solenoid valve specification

\begin{tabular}{c|c} 
Valve Model & Uflow PCN28 \\
\hline Type & 2-WAY $(\mathbf{N C})$ \\
\hline Action & Diaphragm \\
\hline Power & Solenoid \\
\hline Coil voltage & 220 volt \\
\hline Coil power & 6.5 wC coil \\
\hline Flow Factor $\left(\boldsymbol{K}_{\boldsymbol{v}}\right)\left(\boldsymbol{m}^{3} / \boldsymbol{h r}\right)$ & $\mathbf{3 . 2}$ \\
\hline Orifice $(\mathbf{m m})$ & $\mathbf{1 6 . 5}$ \\
\hline Port size & $\mathbf{0 . 5}$ inch \\
\hline Operating Pressure & $\mathbf{0 . 5 - 1 2}$ bar \\
\hline Seal \& Diaphragm material & NBR/VITON/EPDM \\
\hline Response time, $\boldsymbol{T}_{\boldsymbol{c}}$ & Less than $20 \mathrm{~ms}$
\end{tabular}

The CAV, shown in Fig. 5, is supplied with orifice hole located at the connection between the CAV and pipeline $\mathrm{T}$ junction. 


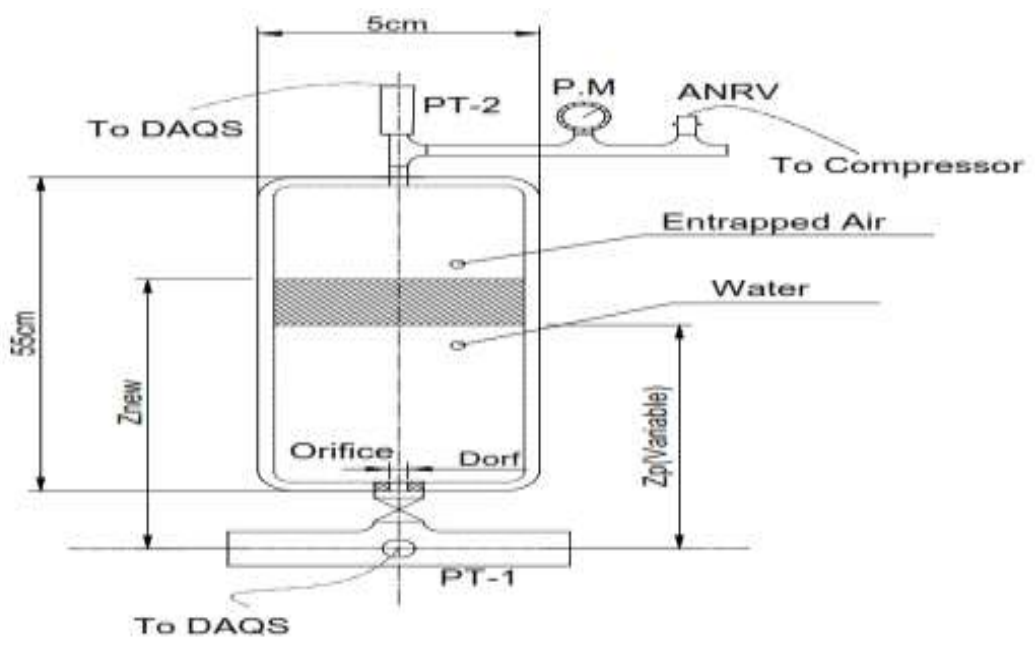

Fig.5 Air vessel with the appurtenances

Initially, the experiment is operated in isolation from the CAV by closing the ball valve installed between the main pipe and CAV. The RCV is operated to create a water hammer and the pressure rise is recorded via pressure transducer [PT1]. Thereafter, the test is repeated with connecting the CAV where the water enters the CAV to certain level according to force balance. The CAV is tested at three different

values of volume fraction ratio, VFR (Volume of air/vessel volume) $(78 \%, 60 \%$ and $53 \%$ ). At each VFR, three sizes of orifice diameter 4, 6 and $8 \mathrm{~mm}$ are tested.

\section{Results and Discussions}

Four different cases have been examined in the current study as follows

\subsection{Case.1 Pipeline without transient control device}

In this case the RCV closes suddenly and is kept closed for $3.2 \mathrm{~s}$ to reach steady state, then the RCV opens. Both experimental and modeled pipeline system are presented in Fig. 6. There is good agreement between both results. Due to water hammer phenomena, the maximum experimental pressure rise is $302 \mathrm{~m}$, while the simulated result deviates by $4.5 \%$. These values are in good agreement with the water hammer relation $(\alpha \Delta v / g=1000 \times 3 / 9.8=300 \mathrm{~m})$. Negative pressure values show up in the early stage of water hammer. In addition, there is a second acute pressure rise at $80 \mathrm{~m}$ for the experiment and $40 \mathrm{~m}$ for the model. The periodical time of the 
pressure wave is nearly $0.059 \mathrm{~s}$ which is very close to the well-known water hammer relation (four times the pipe length over the speed of sound in water).

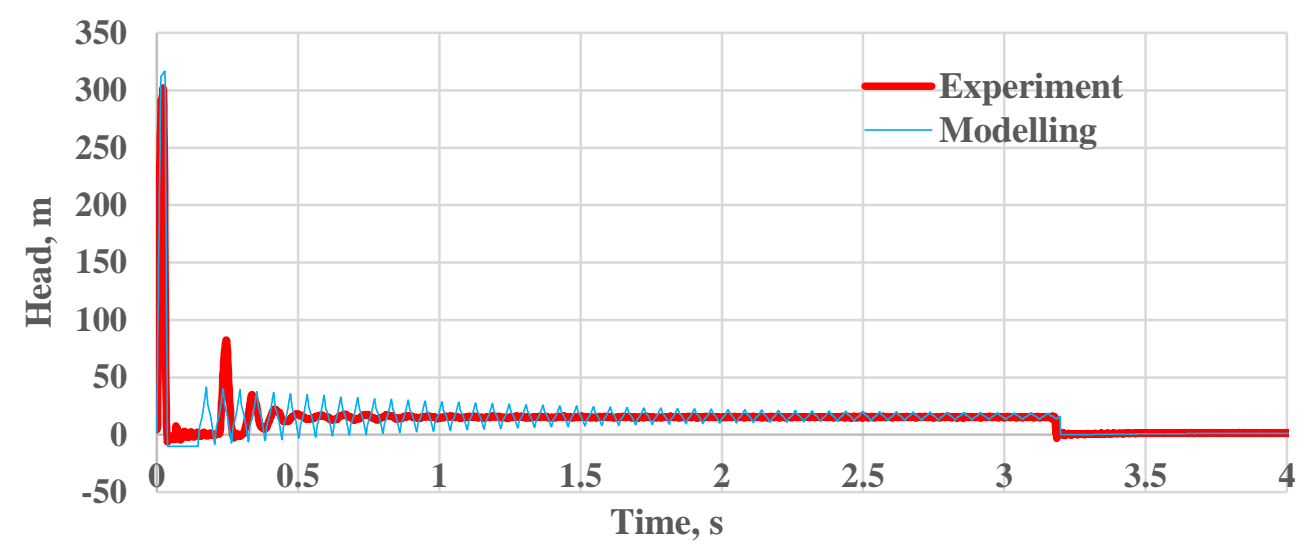

Fig. 6 Pressure Rise due to water hammer for experimental and theoretical case study without protection

\subsection{Case.2 Pipeline with air vessel}

The effect of installing of CAV, just before the valve, on the pressure rise during water hammer is modelled and tested experimentally at 4, 6 and $8 \mathrm{~mm}$ orifice diameters and 12, 22 and $26 \mathrm{~cm}$ water column height corresponding with VFR 78\%, $60 \%$ and $53 \%$ respectively. Samples of these experiments compared with the simulated results are presented in Fig.7 for orifice diameter $4 \mathrm{~mm}$ and 53\% VFR. As the valve closes the pressure increases sharply, then decreases to a minimum value and then recovers slowly to the pump pressure. The maximum pressure head rise due to water hammer is lowered from $302 \mathrm{~m}$ (in case of water hammer without any control device) to $48.4 \mathrm{~m}$ ( $84 \%$ reduction). The corresponding model value $51 \mathrm{~m}$ with about 5\% deviation. As the valve opens, the experiment shows another sudden increase in pressure, but the model does not show that. Both experiment and simulated results drop to almost the same back pressure at valve position. Since there is a pipe connecting the valve with the water tank, the valve back pressure is above the atmospheric pressure by about $1.5 \mathrm{~m}$.

The rise in pressure of the trapped air inside the air vessel, is shown in the Fig. 8 for both experimental and simulated results. During normal operating conditions, there is a force balance at the vessel entrance so that the pressure at flowing water in the pipe is equal to the pressure of water column in the vessel. As soon as the valve closes, the pipe pressure is suddenly increases causing inflow of water into the vessel which acts as piston compressing the air inside the vessel. The air behaves as a first order system where the pressure increases until it reaches a steady state. As the valve opens, the pressure again decays exponentially. 


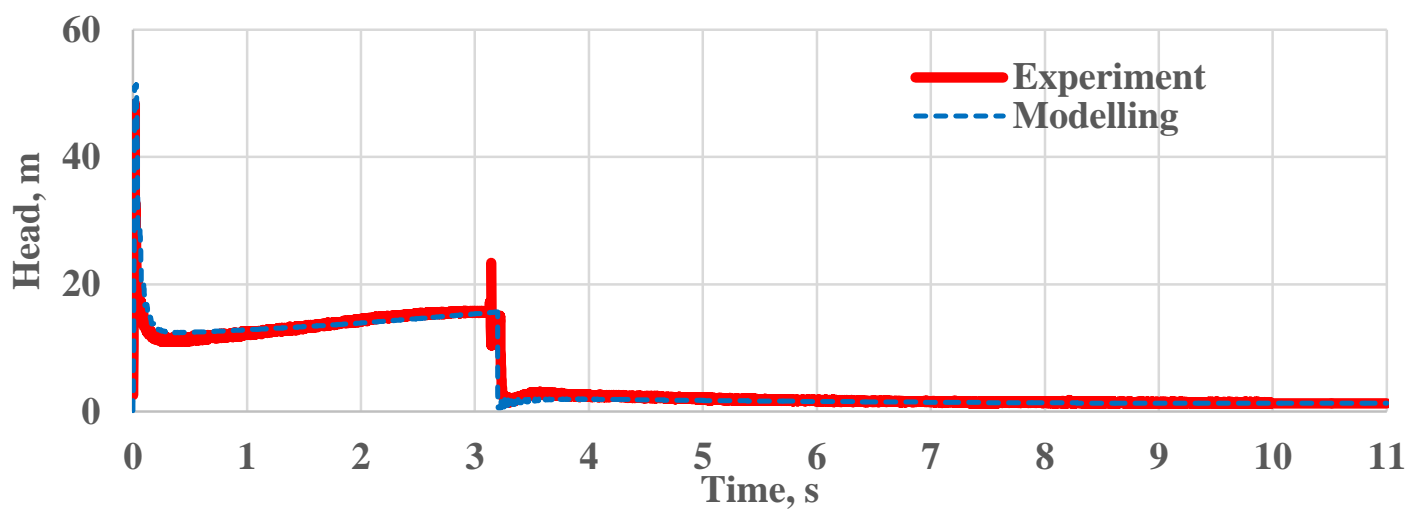

Fig.7 Water pressure built up due to water hammer with air vessel of $O R D=4 \mathrm{~mm}$ and $\mathrm{VFR}=\mathbf{5 3 \%}$

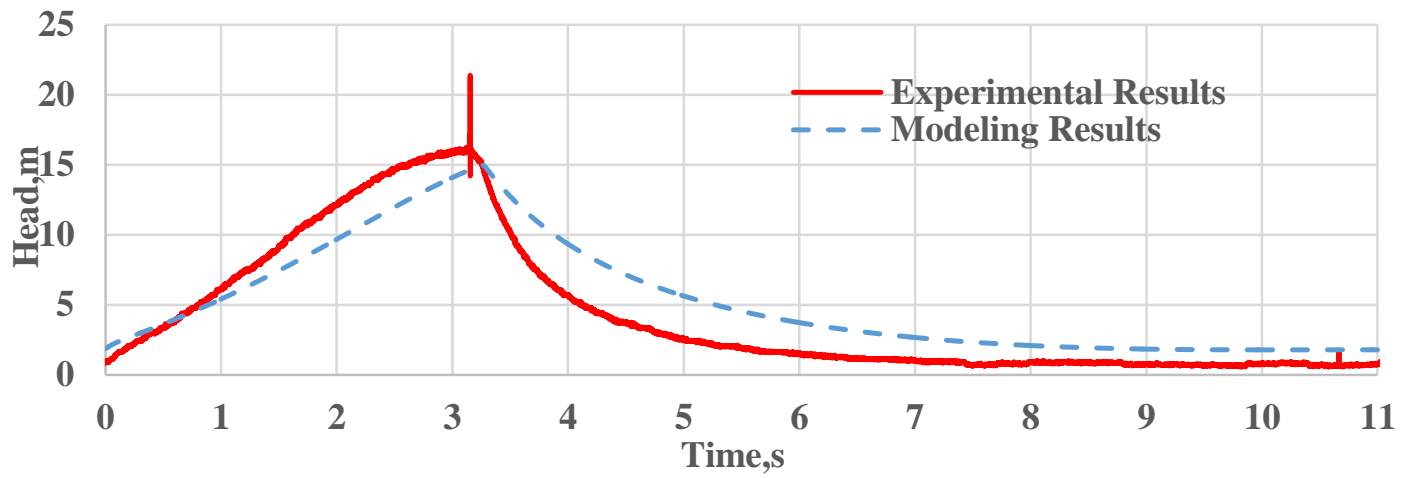

Fig.8 Air pressure head rise inside the air vessel of $O R D=4 \mathrm{~mm}$ and $\mathrm{VFR}=53 \%$

The effect of orifice diameter on the maximum head rise is shown in Fig. 9 for three values of VFR. It is clearly evident that increasing orifice diameter reduces the effect of water hammer. It is also evident that increasing the initial volume of air inside the CAV reduces the maximum head rise during water hammer development. Also, from the experimental results in Fig. 9 there is no effect of VFR for more than $60 \%$.

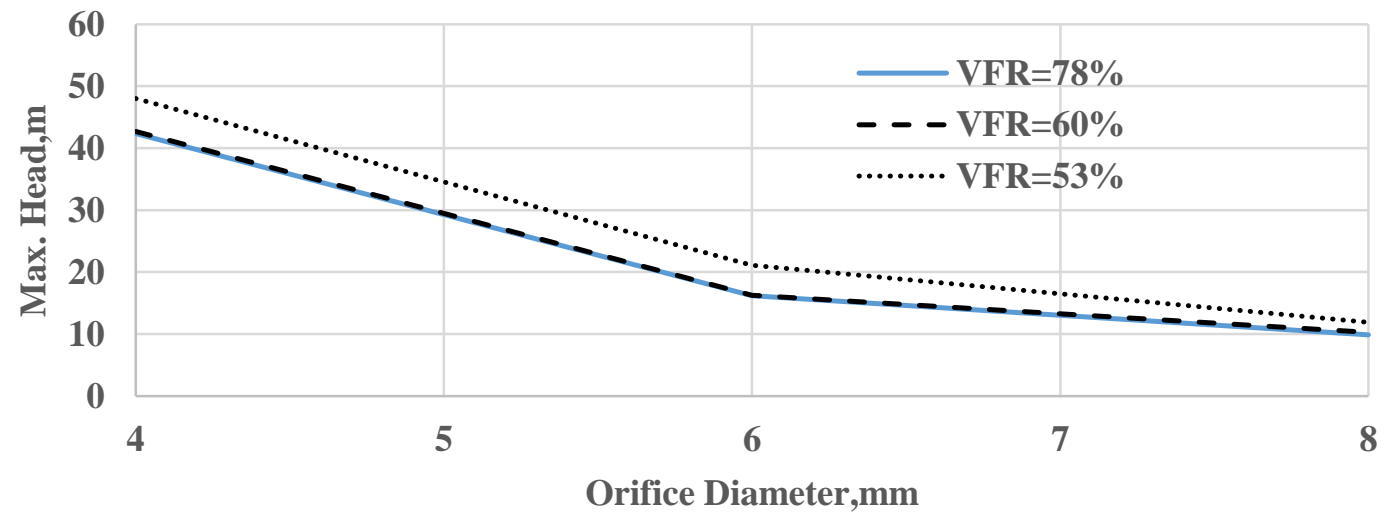


Fig. 9 Experimental maximum head rise VS orifice diameter using CAV

The fluctuation of water column level inside the air vessel is also important to be examined, as it will affect the maximum height of the vessel. This height was monitored virtually during the experiment and was listed in Table.4 as illustrated below.

TABLE.4 Initial and final height of water column inside the CAV

\begin{tabular}{c|c|c|c|c|c|c|c|c|c} 
Orifice diameter & \multicolumn{3}{|c|}{$4 \mathrm{~mm}$} & \multicolumn{3}{c|}{$\mathbf{6 m m}$} & \multicolumn{3}{c}{$8 \mathrm{~mm}$} \\
\hline VFR\% & $\mathbf{7 8}$ & $\mathbf{6 0}$ & $\mathbf{5 3}$ & $\mathbf{7 8}$ & $\mathbf{6 0}$ & $\mathbf{5 3}$ & $\mathbf{7 8}$ & $\mathbf{6 0}$ & $\mathbf{5 3}$ \\
\hline Initial Height & $\mathbf{1 2}$ & $\mathbf{2 2}$ & $\mathbf{2 6}$ & $\mathbf{1 2}$ & $\mathbf{2 2}$ & $\mathbf{2 6}$ & $\mathbf{1 2}$ & $\mathbf{2 2}$ & $\mathbf{2 6}$ \\
\hline Final Height & 33.5 & $\mathbf{3 9}$ & $\mathbf{4 2 . 5}$ & $\mathbf{3 9}$ & $\mathbf{4 3 . 5}$ & $\mathbf{4 6}$ & $\mathbf{3 9}$ & $\mathbf{4 3 . 5}$ & $\mathbf{4 6}$
\end{tabular}

The following Figures 10-12 show the fluctuation of height of water column inside the air vessel, calculated by the mathematical modeling.

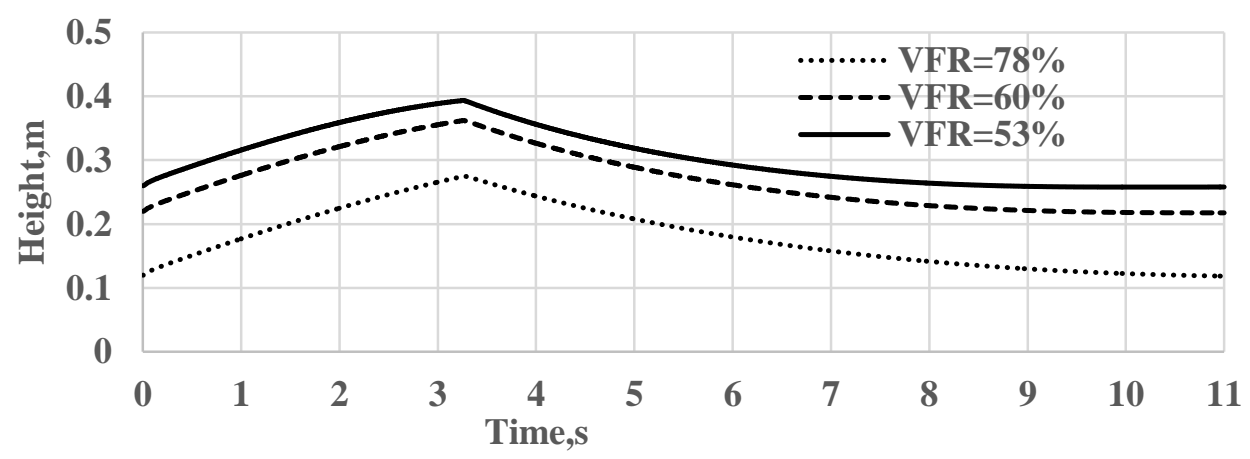

Fig. 10 Height fluctuation of water column inside air vessel with $O R D=4 \mathrm{~mm}$

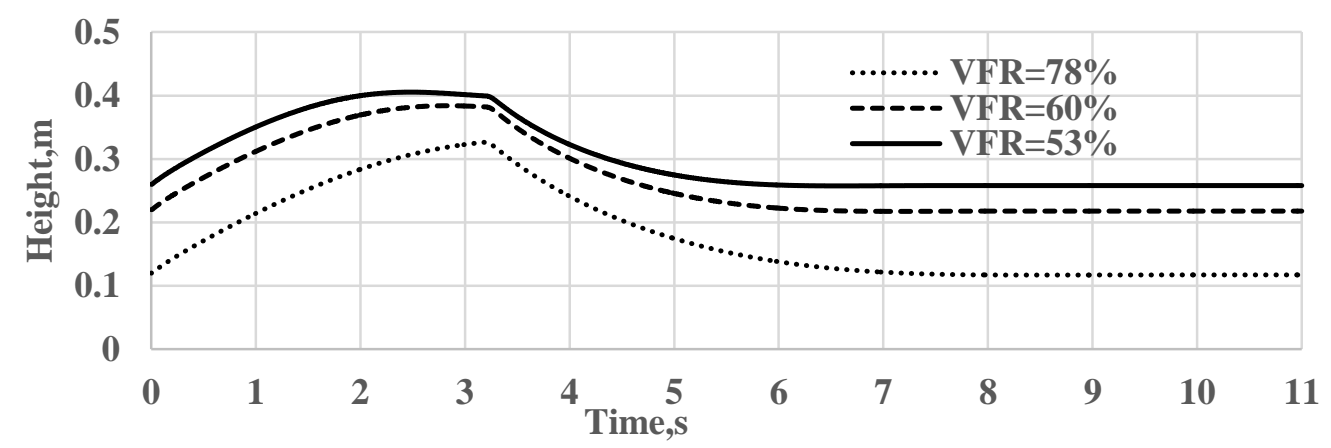

Fig. 11 Height fluctuation of water column inside air vessel with $O R D=6 \mathrm{~mm}$ 


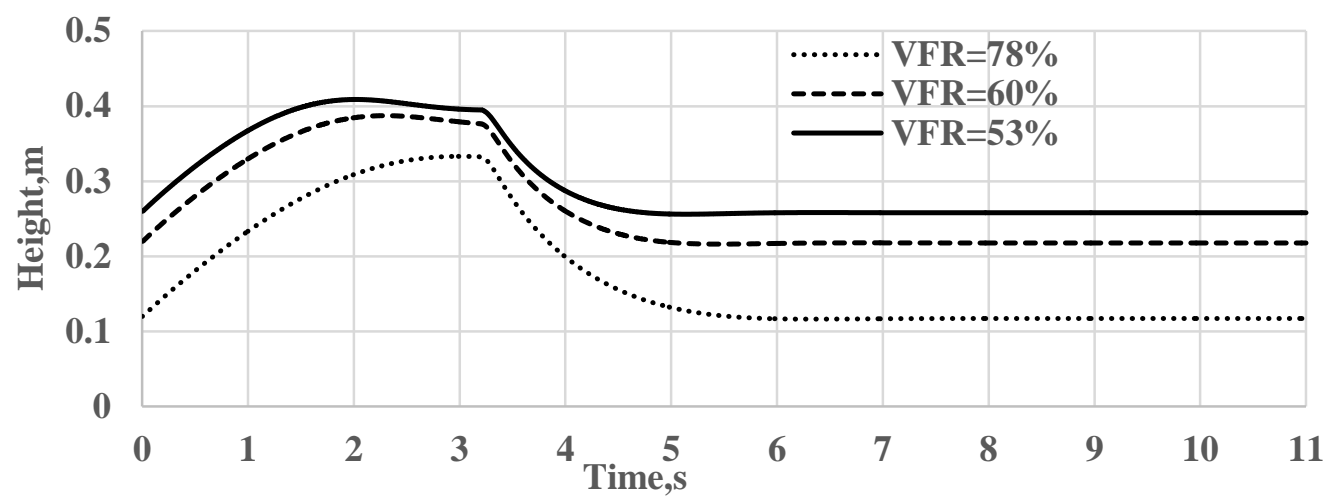

Fig. 12 Height fluctuation of water column inside air vessel with $O R D=8 \mathrm{~mm}$

\section{Conclusions:}

In this paper, the compressed air vessel demonstrates good ability to control the upper and lower limits of pressure inside the pipeline. The effect of the initial volume of trapped air and orifice diameter on the performance of air vessel is simulated and tested experimentally. The following points can be concluded:

1. Quasi-one-dimensional model is capable for modelling CAV during transient flow conditions.

2. Increasing the volume fraction ratio of trapped air inside the vessel decreases the sudden pressure rise due to water hammer, provided that air does not enter the pipeline during the suction period.

3. The initial volume of confined air is limited between lower and upper values, as it cannot exceed $78 \%$ of the vessel's total volume, so that the air can enter the pipeline and cannot be less than 53\% of the total volume of the vessel, so that the damping effect of the trapped air is trivial.

4. The optimal limit volume fraction ratio (VFR) is shown to be $60 \%$, above this value shows no effect on the values of pressure.

5. Throttling the aperture of the air vessel provides a resistance to the inlet flow which affects the size of the air vessel and make the trapped air to be compressed gradually.

6. Throttling the aperture of the air vessel reduces the mass oscillation of water, which reduces the size of the air vessel.

7. The diameter of the orifice should be sized, so that the minimum diameter to be $30 \%$ of that of the main pipe.

8. The experimental results confirmed the good agreement with the model results, so it can be used as a tool for optimizing air vessel parameters. 


\section{References:}

1. A.K.Arya, L.K.Mylapilli and P.V.Reddy Gogula, Hydraulic and surge analysis in a pipeline network using pipeline studio, IJERT,Vol.4, February-2015

2. I.Abuaziah, A.Oulhaj, K.Sebari, A.A.Saber, D.Ouazar, and N.Shakameh , Modeling and Controlling flow Transient in Pipeline Systems, Mar.Sci.Argon, pp.12-18, 2013

3. M.S.Ghidaoui, M.Zhao, D.A.Mclnnis and D.H.Axworthy, Review of Water Hammer Theory and Practice, Applied Mechanics Reviews. 58, 1(2005), pp. 49-76

4. M. Salmanzadeh and S. Torfi, Analysis of surge in pipelines systems by characteristics method, IJM,Vol.5,2011

5. R.Wichowski, Hydraulic transients analysis in pipe networks by the method of characteristics (MOC), AHEEM, Vol. 53, pp. 267-291, 2006

6. B.E.Larock and R.W.Larock, Hydraulics of pipeline systems, New York: CRC, 2000.

7. A.R. David Thorley, Fluid Transients in Pipeline Systems, 2nd Ed., Uk, PEPL, 2004

8. M.H.Chaudhry, Applied hydraulic transient, 2nd Ed. New York: VNR, 1986.

9. E.B.Wylie and V.L.Streeter, Fluid Transients, New York: McGraw-Hill, 1978.

10. J.Parmakian, Water Hammer Analysis, New York: DP, 1963.

11. G.Z.Watters, Analysis and control of unsteady flow in pipelines, 2nd Ed. Boston: Butterworths, 1984.

12. T.S.Lee, Effects of Air Entrainment on the Ability of Air Vessels in the Pressure Surge Suppressions, J.Fluid.Eng.,vol. 122,September 2000

13. D.Martino and N.Fontana, Simplified Approach for the Optimal Sizing of Throttled Air Chambers, J.Hydraul.Eng., pp.1101-1109, 2012

14. D.Stephenson, Simple guide for design of air vessels for water hammer protection of pumping lines. J. Hydraul. Eng., 128(8), 792-797, 2002.

15. L.Wang, F.J.Wang, Z.C.Zou, X.N.Li and J.C.Zhang, Effects of Air Vessel on Water Hammer in High Head Pumping Station, 6th International Conference on Pumps and Fans With Compressors and Wind Turbines,2013

16. M.Besharat, M.T.Viseu and H.M.Ramos ,Experimental Study of Air Vessel Behavior for Energy Storage or System Protection in Water Hammer Events , Water,Jan.2017

17. A.Jamal, M.Najarchi and S.M.M.Najafi Zada, Designing Hydraulic Air Chamber in Water Transmission Systems Using Genetic Algorithm",Adv.in Scien. And Tech.Res.J.,vol.10,no.31,pp.1-7,Sept.2016

18. R.H.Landau, A first course in scientific computing, Fortran version, Princeton university press, New Jersey, 2005 
A.M. Abdulaziz / Engineering Research Journal 167 (septamper 2020) M1- M17

19. I.D.Chivers and J.Sleightholme, Introducing to programming with Fortran, 2nd ed., London ,Dordrecht, Heidelberg, New York :Springer-Verlag, 2012 